\title{
INTRODUCING A TOOL TO SUPPORT REFLECTION THROUGH SKETCHING AND PROTOTYPING DURING THE DESIGN PROCESS
}

\author{
B. Jobst ${ }^{1,2, \otimes}, \mathrm{K}$. Thoring ${ }^{1,2}$ and P. Badke-Schaub ${ }^{2}$ \\ ${ }^{1}$ Anhalt University of Applied Sciences, Germany, ${ }^{2}$ Delft University of Technology, The Netherlands \\ $\triangle$ birgit.jobst@hs-anhalt.de
}

\section{Abstract}

Sketching and prototyping are parts of a 'reflective conversation with materials of a design situation' (Schön, 1992). To support this conversation, we developed a reflective tool -the Reflection Canvas- that facilitates reflection activities through sketching and prototyping on the one hand and verbalisation on the other. We introduced the reflective tool to design students. Based on observation and answers from a questionnaire data reveal that guided reflection structured the process in a helpful way. It also turned out students had difficulties to switch from visualisation to verbalisation.

Keywords: decision making, design methods, reflection, prototyping, sketching

\section{Introduction}

Sketching and prototyping are appropriate methods when dealing with complex and complicated requirements of design problems. Both visualisation methods seem to be most successful when implemented in the early phases of design processes (Römer et al., 2000). Goldschmidt (2002) stresses the flexibility of using visual representations as the "ability to use the representational act to reason on the fly" (Goldschmidt, 2002, p. 72). In addition to these benefits, manual sketching fortifies reasoning (Goldschmidt, 2017). Other empirical studies have shown that early sketching and prototyping is connected with a better estimation of risks and a more suitable cost calculation (Ehrlenspiel and Meerkamm, 2013). Moreover, sketching and prototyping do not only affect cognitive processes but also motivational processes. Research revealed that sketching and prototyping is positively related to enhanced self-efficacy (Dow et al., 2012; Gerber and Carroll, 2012). This relation between prototyping and self-efficacy has consequences for the individual motivation and also for success expectations (Bandura, 1989).

Another important method aiming to improve the outcome of thinking and decision-making processes is reflection (Dörner, 2011). Although there are different disciplines showing that reflection has a positive influence on process and outcome (Mann et al., 2009) there is no common overarching theory that tries to explain the different interactions of thinking processes and their implications. We started from the assumption that the switch between visualisation and verbalisation is creating a thinking pattern that is beneficial for coping with complex design problems (Badke-Schaub and Dörner, 2002). Based on this assumption, our aim is to further explore the interrelations of both methods, sketching and prototyping on the one hand, and reflection on the other. This lexd to the following research questions: 
$R Q$ 1: How to support designers' reflection (on the design process) through sketching and prototyping?

$R Q$ 2: How to develop a tool that facilitates switching between verbalisation and visualization in order to support reflection?

\section{Theoretical foundation}

"Designers work in a medium" (Schön and Wiggins, 1992, p. 154) meaning that designers are using different media such as drawing, sketching, and prototyping. Designers see the product of their work evolving and thus develop a thorough understanding (Schön and Wiggins, 1992, p. 156) of the task and they create knowledge and experience in dealing with this kind of task. This understanding is an intermediate output of design that guides and stimulates the ongoing design process. In order to establish this learning process, reflection needs to be integrated into the design process. This learning process can be observed and analysed and designers need to reflect on this process in order to be able to integrate and make use of the learning during the design process. Sketching and prototyping are alternatively accompanying ways of creating and building on ideas during the earlier initial phases of the design process and they represent the designer's way of visualising their mental processes (Schütze et al., 2003) and images. Definitions regarding reflection are diverse and vary between disciplines, such as psychology (Gibbs et al., 2013), philosophy (Dewey, 1933), education (Biggs and Tang, 2011; Bloom, 1956; Kolb, 1983; Krathwohl, 2002), among others. Mann et al. (2009) point out that 'most models of reflective practice depict reflection as activated by the awareness of a need or disruption in usual practice' (p. 597). The mode of reflection considered here is commonly characterized as individual contemplation about the current situation, known as reflection in action (Schön, 1987), or reflecting on a past situation, known as reflection on action.

According to traditional design process models such as the Pahl and Beitz approach (Pahl et al., 2007), we assume subsequent steps in the design process. The main task for designers in the early design process is to understand the problem and to define and frame the problem. From there the next step, the generation of ideas, is linked to creativity and innovation (Goldschmidt, 1997; Sachse et al., 2004). The ideation phase can be methodologically supported by creativity techniques, for example, brainwriting and brainstorming (Kumar, 2012).

We define reflection as a dynamic process of a unique pattern of activities steered by continuous awareness. This pattern of activity will be executed in the moment where awareness signals a new, dangerous or surprising cue. Figure 1 visualises reflection as a two-step process combining two different thinking processes; awareness and activities.

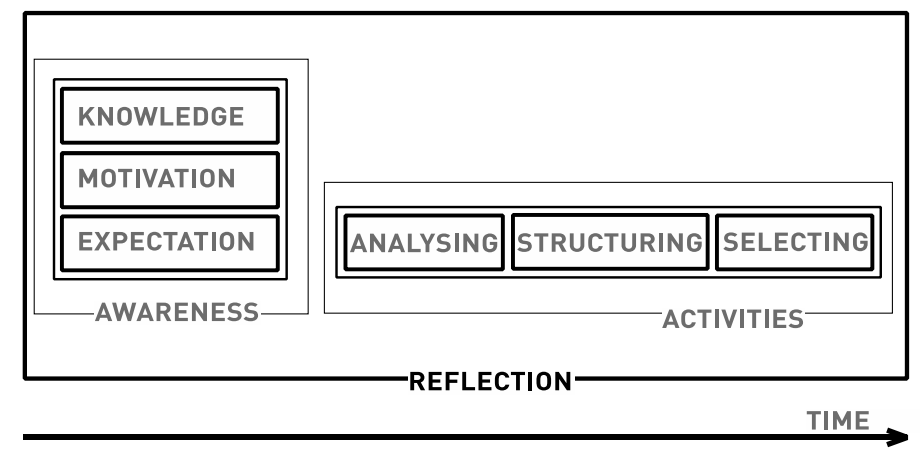

Figure 1. Reflection defined as a combination of awareness and verbalized activities

Awareness can be described as a background control system that works continuously to ensure that the current situation does not deviate from the expected situation. Only in the moment when a cue indicates newness, surprise, or danger, the activity of reflection will be initiated. In short, awareness prepares the brain to react in situations when a moment occurs that needs further attention and thus initiate activities such as analysing, structuring, and selecting, which can raise a better understanding of the current situation. In short, in case a situation turns out to be different from the own mental model, the routine answer cannot be applied - maybe because something new or different occurs than 
usual or a completely new situation which cannot be solved by applying well known patterns of the solution. To raise reflection, a person has not only to be aware of a critical situation but also the person has to be motivated to act based on own knowledge about how to apply or how to generate an answer to the current problem.

The second part of the definition describes a pattern of activity (see Figure 1) which provides a better understanding of the situation as consisting of the activities how to react and how to learn from it. This described process is not easy, it needs the openness of being aware that a situation is different than expected and in addition it needs cognitive capacities to act in a suitable way. This process can be trained and it is of special interest in the sketching or prototyping situation, where the designer is often thinking intuitively rather than consciously.

In parallel to visualisation, verbalizing thoughts and ideas have been shown to be supportive for reasoning (Wetzstein and Hacker, 2004). Thus, it is at stake to think about how to improve this reflection process.

\section{Methodological approach}

The aim of this investigation is twofold: The first aim is to support the designer's reflection through sketching and prototyping, and the second aim is to find out how to facilitate the switch between visualisation and verbalisation during the design process. Of course, human beings use both representations; however, the switch is not necessarily planned but occurs due to individual preferences or by chance.

The chosen research approach is a standard example for action research that has been established as research philosophy and research methodology in the social sciences almost eight decades ago. Kurt Lewin, the famous Gestalt psychologist coined the term in his paper Action Research and Minority Problems (Lewin, 1946) and describes action research as a transformative change in a process of taking action and doing research at the same time, bound by critical reflection. Action research allows the researcher to intervene in a given situation and then analyse the changes that can be evaluated as influence due to the intervention.

In order to answer our research questions, our goal was to develop a tool that facilitates reflection and to apply and validate this tool as an intervention in a workshop setting. Nine design students took part in the workshop. The group consisted of four male and five female designers, all Bachelor students have been from the department of Integrated Design at Anhalt University of Applied Sciences, Germany. We followed Kemmis' four-step-action-research cycle (Kemmis et al., 2013) covering the following activities:

Step 1: Plan. We planned an intervention that should give us first answers to our research questions and we developed and designed a tool (the Reflection Canvas).

Step 2: Act. We created a common environment, that was a workshop with a special design task which had to be solved in seven hours.

Step 3: Observe. The participants were observed during the workshop and had to answer questions related to the research questions.

Step 4: Reflect. At the end of the workshop a questionnaire was handed out to the participants.

The tool had to be developed in a way that all aspects of reflection were implemented as well as the switch between verbalisation and visualisation. Thus, relevant activities for reflection - analysing, structuring, and selecting - were chosen and implemented in the reflective tool. The tool had to be designed in a way that designers reflect their visualisation by verbalisation and create visualisations by verbalisations. We decided to design the tool as a canvas, because a canvas structures a complex task into smaller components and guides a team through a process (Thoring et al., 2019). Consequently, a canvas can facilitate participants to work together on a task and guide them through the instructions on the canvas. Furthermore, it is possible to write down comments etc. directly on the canvas which supports verbalisation and visualisation of ideas.

We expect several benefits when following and using Reflection Canvas. The use of the Reflection Canvas should: (a) raise awareness for new situations; (b) increase knowledge on how to apply reflection activities; and (c) lead to positive experiences of the participants. 
For developing the Reflection Canvas, we followed three consecutive steps. First, we built on insights from practice to compose the content of the Reflection Canvas. We discussed the topic of reflection with experienced teachers in design education as well as with design practitioners. We extracted relevant methods and interventions regarding the three activities for reflection: analysing, structuring and selecting. We formulated requirements and objectives for the intended solution: a developed Reflection Canvas to support reflection through sketching and prototyping. The Reflection Canvas aims at (creating an awareness for) a situation to facilitate that students stride through the reflection process by following the steps on the Reflection Canvas. Secondly, we conceptualized the Reflection Canvas building on the theoretical assumptions that were depicted in Figure 1. Thirdly, selected methods and interventions have been structured and organised regarding guidelines from Gestalt Theory (Arnheim, 2013). Nine building blocks with short instructions make the Reflection Canvas self-explanatory. Each building block has a headline for quick understanding of the overall aim and on a second level in smaller font sizes some instructions that should be followed by the participants. The addressed activities are linked to instructions on the Reflection Canvas.

The developed tool was evaluated during the workshop and the results were evaluated in regard to the research questions. After the workshop, a questionnaire had to be filled in with two types of questions to tick. closed questions with choices "yes", "no", or "I don't know". (Example: Do you plan to implement parts of the Reflection Canvas for future work?). In addition, there were Likert scaled questions from 1-5 (5 signifies the highest extent). For example, we asked for perceived self-efficacy when working on complex design problems. Furthermore, participants were asked how often they make use of sketching and prototyping to support reflection.

\section{Results}

In this section the Reflection Canvas will be introduced as well as its application and evaluation in the workshop. Furthermore, observations made in the workshops and results from the questionnaire will be reported.

\subsection{Workshop as intervention: The Reflection Canvas}

The Reflection Canvas consists of nine building blocks. The aims of each step as well as intended activities are described in Table 1.

Table 1. Composition of nine activities during the design process

\begin{tabular}{|l|l|c|c|c|}
\hline & Aim & Analysing & Structuring & Selecting \\
\hline 1 & $\begin{array}{l}\text { Defining: The aim is to define and document the project and the project } \\
\text { owners and responsibilities. }\end{array}$ & - & - & - \\
\hline 2 & $\begin{array}{l}\text { Developing insights. The aim is to verbalise and write down relevant } \\
\text { information, starting with user information, expert knowledge but to } \\
\text { stimuli or inspirational moments, materials, shapes, surfaces, colour for } \\
\text { you? }\end{array}$ & $\mathrm{X}$ & $\mathrm{X}$ & $\mathrm{X}$ \\
\hline 3 & $\begin{array}{l}\text { Framing. The aim is to decide to be aware of the direction for the design } \\
\text { process }\end{array}$ & $\mathrm{X}$ & $\mathrm{X}$ & $\mathrm{X}$ \\
\hline 4 & Building criteria. The aim is to verbalise criteria and prioritize the criteria. & $\mathrm{X}$ & $\mathrm{X}$ & $\mathrm{X}$ \\
\hline 5 & $\begin{array}{l}\text { Collecting ideas. The aim is to verbalise the underlying design idea of } \\
\text { own sketches/prototypes. Visual and verbal representation may require } \\
\text { different levels of maturity and resolution. }\end{array}$ & $\mathrm{X}$ & $\mathrm{X}$ & \\
\hline 6 & $\begin{array}{l}\text { Structuring information. The aim of structuring into the two-axis matrix } \\
\text { is to facilitate the visualization of dependencies and relations between } \\
\text { two criteria. }\end{array}$ & $\begin{array}{l}\text { Analysing interrelations and interdependencies of ideas as well as } \\
\text { strengths, weaknesses and potentials for a further concept. }\end{array}$ & $\mathrm{X}$ & $\mathrm{X}$ \\
\hline 8 & $\begin{array}{l}\text { Voting and deciding. The aim is to decide on the basis of relevant } \\
\text { criteria that most fit the problem description and describe the arguments } \\
\text { for the decision. }\end{array}$ & $\mathrm{X}$ & \\
\hline 9 & Forecasting. The aim is to formulate future steps based on reflection. & $\mathrm{X}$ & $\mathrm{X}$ \\
\hline
\end{tabular}


The described activities and steps are arranged on a canvas poster. We designed the Reflection Canvas in the size of a DinA0 (841 x $1189 \mathrm{~mm})$ and with a horizontal format that is intended to be used wall mounted (Figure 2).

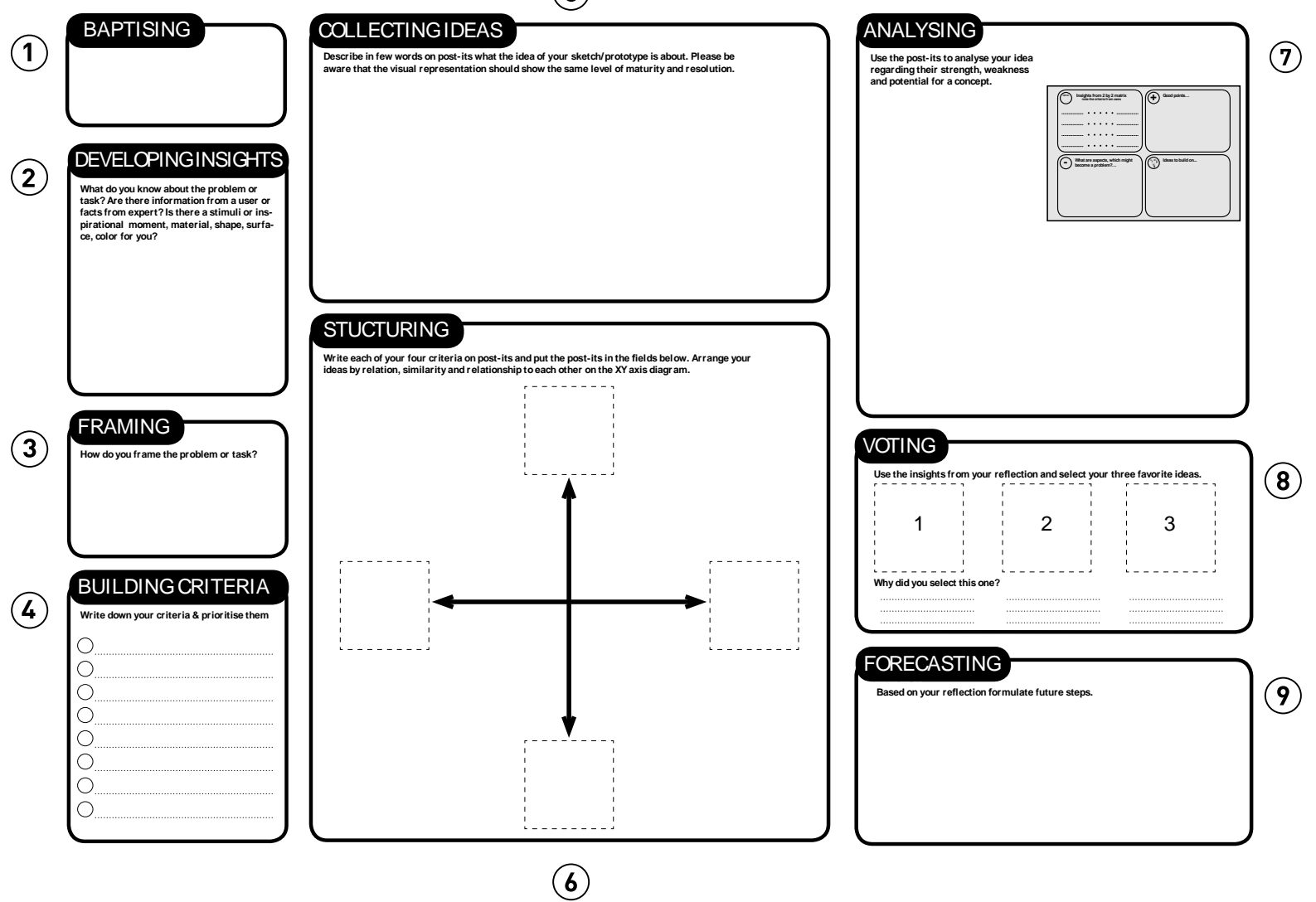

Figure 2. Reflection Canvas a template for the application of reflection activities

To learn more about the interaction of design students faced with the Reflection Canvas we evaluated it in a conceptualised workshop. Results from evaluation are presented in the next section. In the beginning of the workshop an introduction of the theoretical background with special emphasis on the reflecting activities was given. Furthermore, the Reflection Canvas was introduced as tool and how to use it. Two student teams (between 4-5 students) received the task to design a stool. The stool is intended for short term sitting and for offering the possibility to be carried easily after using it. The prototype of the stool should be in a testable size (1:1) and made out of cardboard (the material was handed out). The teams received the brief with a (different) persona aiming at developing three solution approaches in form of paper prototypes and using the Reflection Canvas while doing so within a day (seven hours). The application of the different steps of the canvas as well as the development of the solution was coached and observed by one researcher. Participants got access to paper prototyping material as tape, cutter, scissor, etc. At the end of the workshop the two teams presented one stool prototype as a result. The process and the results were discussed and feedback was given. All participants answered the questions of the questionnaire. During the workshop photos and notes were taken with permission from the participants. The answers were analysed and interpreted and are presented in Section 4.2. In the following the results of the two research data acquisition methods are presented, behaviour observation.

According to the results, the participants considered the Reflection Canvas as understandable and (almost) self-explanatory. The first step of the participants was analysing the problem and to generate an understanding for the need of the given persona in order to derive relevant insights. Building on that, the participants should develop a frame and derive criteria in order to start generating ideas. We observed that the participants jumped between task and first ideas, which were 
sketched or realised as quick prototypes (in paper or collages) for a solution. The following observations were made.

(a) Before verbalising and formulating the insights, the framing and criteria first ideas were already generated. The steps were not followed and made in a structured way. The coach intervened to remind them to take structured approaches into consideration. (b) Both teams struggled with the verbalisation of underlying ideas when they had to write them on post-its (which was the basis for structuring ideas).

(c) Verbalizing the frame and criteria as well as prioritizing the criteria seemed to be very difficult for the participants. Criteria were formulated vaguely (they used words like "modern", "sustainable", "appealing for young people", "functional"), which made the later design less straight and more arbitrary. (d) Prioritising of criteria resulted in longer discussions within the teams (and was very time-intensive). Analysing each idea based on a sketch/prototype seemed to be quite difficult for the teams because they had to formulate verbally the strengths and weaknesses of each idea. In this situation the groups experienced an information deficit. It seemed that the instruction to analyse pros and cons of an idea caused a deeper reflection process. From the beginning to the end of the process participants showed a more open and less emotional attitude regarding their favourite idea. In the beginning the Reflection Canvas seemed for the teams to be considered as time consuming, but this attitude changed after a first application. Verbal reflection within the team was triggered in parallel the making of further sketches and prototypes. The switch of sketching and prototyping and changing to verbalisation seemed to become more and more accepted (and considered as being supportive).

\subsection{Results of the questionnaire}

The participants were asked to pin down the three most relevant aspects of the Reflection Canvas for reflecting. All of the participants (9/9) considered as being important to formulate criteria and to bring the criteria into a sequence and to note them down on Reflection Canvas and to use it for analysing, structuring, selecting sketches and prototypes. They mentioned that criteria are supportive: (a) to limit the scope of the topic, (b) to give guidance, (c) to stay focussed, and (d) to work purposefully.

Another part of the Reflection Canvas mentioned above is 'insights' and the explanation why insights are useful. The participants answered: It is 'important to visualise, thus insights stay present and are not getting lost' (P9); 'if you do not analyse the problem carefully many problems will arise later in the process' (P4). In addition, participants appreciated to write down the framing (4/9) and consider it as 'support in creating a frame in order to avoid getting lost in idea generating' (P8). Another participant stressed the guidance of framing: 'gives you a directory for the project' (P5).

The Participants were asked if they would integrate parts of the Reflection Canvas in their future design process? Most participants (5/9) would integrate process steps of the Reflection Canvas in their future design process. Some mentioned to plan the implementation of specific steps of the Reflection Canvas: (a) Relevant criteria are framing and analysing, and (b) One participant answered to implement all nine blocks 'because in total it is a good directory for the process'(P5). Table 2 shows the answers of the nine participants (P1-9) in regard to selected items of the survey. The results indicate a link between perceived self-efficacy regarding complex problem-solving and reflection as well as prototyping activity to support reflection. For example, participant (P1) with the highest perceived self-efficacy in complex problem solving (5/5) and the highest self-efficacy regarding reflection mentioned to use sketching on an extent of $60 \%$, to use sketching for supporting reflection quite often (scale: 4/5), to use prototyping for reflection very often (5/5), and to implement prototyping on an extent of $90 \%$. The participant (P5) with the lowest perceived selfefficacy in complex problem solving (3/5) and less self-efficacy regarding reflection uses sketching (4/5) more often than prototyping (3/5) to support reflection, and describes the extent of sketching activity with $70 \%$ and prototyping activity with an extent of $40 \%$. There are indices that a high activity of prototyping has a link to self-efficacy regarding reflection and complex problem-solving. However, a high activity in sketching seems not to be linked to a high self-efficacy regarding complex problem-solving. 
Table 2. Overview of selected results of the survey

\begin{tabular}{|c|l|c|c|c|c|c|c|c|c|c|}
\hline & Content & P1 & P2 & P3 & P4 & P5 & P6 & P7 & P8 & P9 \\
\hline 1 & $\begin{array}{l}\text { Self-efficacy in regard to reflection } \\
\text { on Likert scale 1-5 }\end{array}$ & $5 / 5$ & $4 / 5$ & $4 / 5$ & $4 / 5$ & $2 / 5$ & $4 / 5$ & $3 / 5$ & $4 / 5$ & - \\
\hline 2 & $\begin{array}{l}\text { Self-efficacy in regard to problem- } \\
\text { solving on Likert scale 1-5 }\end{array}$ & $5 / 5$ & $4 / 5$ & $4 / 5$ & $4 / 5$ & $3 / 5$ & $4 / 5$ & $4 / 5$ & $4 / 5$ & - \\
\hline 3 & Sketching extent of activity in \% & 60 & 20 & 80 & 40 & 70 & 60 & 70 & 80 & 80 \\
\hline 4 & Prototyping extent of activity in \% & 90 & 30 & 80 & 50 & 40 & 20 & 30 & 40 & 60 \\
\hline 5 & Frequency of sketching for reflection & $4 / 5$ & - & $3 / 5$ & $3 / 5$ & $4 / 5$ & $4 / 5$ & $4 / 5$ & $4 / 5$ & $4 / 5$ \\
\hline 6 & $\begin{array}{l}\text { Frequency of prototyping for } \\
\text { reflection }\end{array}$ & $5 / 5$ & $1 / 5$ & $3 / 5$ & $4 / 5$ & $3 / 5$ & $4 / 5$ & $200 \% *$ & $2 / 5$ & $3 / 5$ \\
\hline
\end{tabular}

* 200\% was the answer of participant 7

who wanted to stress the frequent use of prototyping.

\section{Discussion and conclusions}

We approached our research with two theoretical assumptions. First, that it is possible to support designers' reflection on the design process through sketching and prototyping. Secondly, that our developed tool, the Reflection Canvas, supports design students to switch between verbalisation and visualization in order to facilitate reflection. To answer our research questions, we introduced the developed Reflection Canvas to participants in a workshop. By following the nine steps of the Reflection Canvas, the participants were guided through a reflection process using sketching and prototyping. For an action research project, the fourth step is intended to reflect about the research, to discuss the limitations, and to draw conclusions for future work.

One observation from the action research workshop was that one team did an iteration of ideas and it was not clear for them if they are allowed to do an iterative loop directly on the Reflection Canvas. Some modification of the Reflection Canvas should be done to clarify how to use the Reflection Canvas for iterative cycles.

Based on insights from the questionnaire the Reflection Canvas was evaluated as helpful for guiding through the process. Furthermore, the participants considered it especially supportive to verbalise and prioritise criteria and to write them down. Doing so was considered helpful for progressing. The participants mentioned that it is helpful to verbalise the framing as well as the insights and to write both down in order to have them visible during the whole process. The aspect of visualising interim results on the Reflection Canvas facilitates the short-term memory and can be considered as extended memory, which seems to be supportive as it was mentioned by two participants. However, the observational part revealed that it seemed to be very difficult for the students to verbalize their leading ideas behind their sketches and prototypes. Additionally, it seemed to be difficult to be precise with words especially regarding the selection of criteria. Students learned to apply the reflection activities through the use of sketching and prototyping. There is also an indication that the Reflection Canvas has to be used several times before the benefit might be experienced in a more efficient way. Further research has to be done to be able to generalise these findings.

We can conclude that the developed tool - the Reflection Canvas - is a first step in changing routines in the design process. We think that further interventions are necessary to support more positive experiences with sketching and prototyping in regard to reflection. In summary, we could find a link between self-efficacy regarding complex problem-solving, self-efficacy regarding reflection, high activity in prototyping in regard to reflection, as well as high extent on prototyping. This link comes as no surprise as research already reported a relation between the activity of prototyping and self-efficacy in design problem solving (Dow et al., 2012; Gerber and Carroll, 2012). However, the link between self-efficacy regarding reflection and high activity of prototyping needs further research. Schön's research (Schön, 1992, p. 133) regarding reflective conversation with materials of a design situation takes a closer look on knowing in action and reflection in action. Schön ignores in the 'reflective conversation' to link reflection through representations with verbalisation. Furthermore, self-efficacy regarding reflection is relevant when it comes to increasing reflection for practitioners. 


\section{References}

Arnheim, R. (2013), Kunst und Sehen: Eine Psychologie des schöpferischen Auges, Walter de Gruyter.

Badke-Schaub, P. and Dörner, D. (2002), "Am Anfang war das Wort-oder doch das Bild-oder doch das Wort..."

Bandura, A. (1989), "Regulation of cognitive processes through perceived self-efficacy", Developmental Psychology, Vol. 25 No. 5, p. 729.

Biggs, J.B. and Tang, C. (2011), Teaching for Quality Learning at University: What the Student Does, 4th ed., McGraw-Hill Education (UK).

Bloom, B.S. (1956), Taxonomy of educational objectives. Vol. 1: Cognitive domain, McKay, New York, pp. 20-24.

Dewey, J. (1933), How we think (revised edition), DC Heath, Boston.

Dörner, D. (2011), Die Logik Des Misslingens: Strategisches Denken in Komplexen Situationen, Rowohlt Verlag GmbH, Hamburg.

Dow, S.P. et al. (2012), "Parallel prototyping leads to better design results, more divergence, and increased selfefficacy", Design Thinking Research, Springer, pp. 127-153.

Ehrlenspiel, K. and Meerkamm, H. (2013), Integrierte Produktentwicklung: Denkabläufe, Methodeneinsatz, Zusammenarbeit, 5., überarbeitete und erweiterte., Carl Hanser Verlag GmbH \& Co. KG, München.

Gerber, E. and Carroll, M. (2012), "The psychological experience of prototyping", Design Studies, Vol. 33 No. 1, pp. 64-84.

Gibbs, J.C. et al. (2013), Moral Maturity: Measuring the Development of Sociomoral Reflection, Routledge.

Goldschmidt, G. (1997), "Capturing indeterminism: representation in the design problem space", Design Studies, Vol. 18 No. 4, pp. 441-455.

Goldschmidt, G. (2002), "The backtalk of self-generated sketches”, Design Issues, Vol. 19 No. 1, pp. $72-88$.

Goldschmidt, G. (2017), "Manual Sketching: Why Is It Still Relevant?", In: Ammon, S. and Capdevila-Werning, R. (Eds.), The Active Image: Architecture and Engineering in the Age of Modeling, Springer International Publishing, Cham, pp. 77-97.

Kemmis, S., McTaggart, R. and Nixon, R. (2013), The Action Research Planner: Doing Critical Participatory Action Research, Springer Science \& Business Media.

Kolb, D.A. (1983), Experiential Learning: Experience as the Source of Learning and Development, 2nd ed., Prentice Hall, Englewood Cliffs, N.J.

Krathwohl, D.R. (2002), “A Revision of Bloom's Taxonomy: An Overview", Theory Into Practice, Vol. 41 No. 4, pp. 212-218.

Kumar, V. (2012), 101 Design Methods: A Structured Approach for Driving Innovation in Your Organization, 1st ed., Wiley, Hoboken, N.J.

Lewin, K. (1946), “Action Research and Minority Problems”, Journal of Social Issues.

Mann, K., Gordon, J. and MacLeod, A. (2009), "Reflection and reflective practice in health professions education: a systematic review", Advances in Health Sciences Education, Vol. 14 No. 4, pp. 595-621.

Pahl, G. et al. (2007), Konstruktionslehre: Grundlagen Erfolgreicher Produktentwicklung Methoden Und Anwendung, 4th ed., Springer Berlin Heidelberg, Heidelberg.

Römer, A., Leinert, S. and Sachse, P. (2000), "External support of problem analysis in design problem solving", Research in Engineering Design, Vol. 12 No. 3, pp. 144-151.

Sachse, P., Hacker, W. and Leinert, S. (2004), "External thought—does sketching assist problem analysis?", Applied Cognitive Psychology, Vol. 18 No. 4, pp. 415-425.

Schön, D. (1987), Educating the Reflective Practitioner, Towards a New Design for Teaching and Learning in the Professions, Jossey-Bass San Francisco.

Schön, D. (1992), "Designing as reflective conversation with the materials of a design situation", Research in Engineering Design Theory, Applications, and Concurrent Engineering, Vol. 3, pp. 131-147.

Schön, D. and Wiggins, G. (1992), "Kinds of seeing and their functions in designing", Design Studies, Vol. 13 No. 2, pp. 135-156.

Schütze, M., Sachse, P. and Römer, A. (2003), "Support value of sketching in the design process", Research in Engineering Design, Vol. 14 No. 2, pp. 89-97.

Thoring, K., Mueller, R.M. and Badke-Schaub, P. (2019), "Exploring the Design Space of Innovation Canvases", Research Perspectives in the Era of Transformations, presented at the Academy for Design Innovation Management Conference, London.

Wetzstein, A. and Hacker, W. (2004), "Reflective Verbalization Improves Solutions-the Effects of QuestionBased Reflection in Design Problem Solving", Applied Cognitive Psychology, Vol. 18 No. 2, pp. 145-156. 